
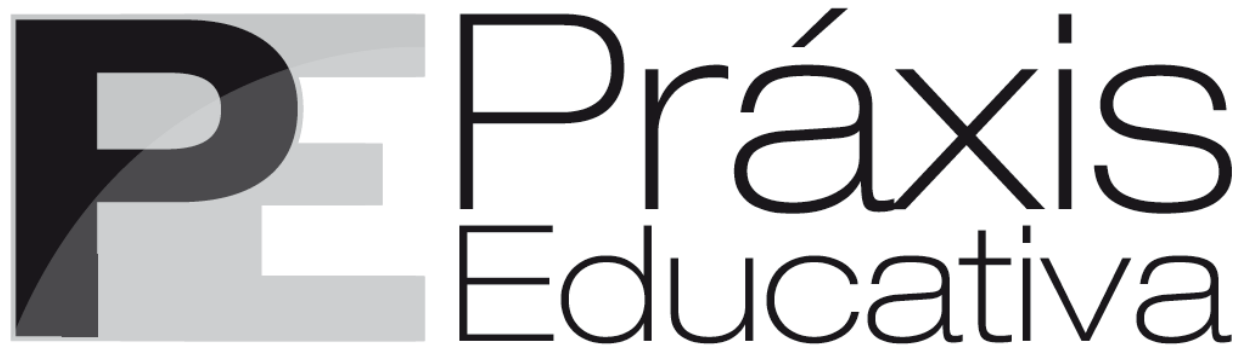

ISSN 1809-4309 (Versão online) DOI: 10.5212/PraxEduc.v.11i3.0014

\title{
Políticas de avaliações externas: ênfase nas competências cognitivas e socioemocionais
}

\section{External evaluation policies: emphasis in the cognitive and socioemotional competences}

\section{Políticas de evaluaciones externas: énfasis en habilidades cognitivas y socioemocionales}

\author{
Elma Júlia Gonçalves de Carvalho* \\ Jane Eire Rigoldi Santos ${ }^{* *}$
}

Resumo: Este artigo apresenta reflexões sobre as políticas brasileiras de avaliação externa com o objetivo de questionar a pertinência da ênfase que tem sido dada às competências. Para isso analisaremos os objetivos, os fundamentos e as matrizes de referência da Prova Brasil e o Projeto SENNA, relacionandoos às novas exigências do capital e aos direcionamentos das organizações internacionais a partir dos anos de 1990. Conforme a análise, incialmente, as avaliações externas tinham uma perspectiva conteudista e, posteriormente, passaram a orientar-se pelo modelo de competências, influenciando na forma como os professores avaliam e a maneira como operacionalizam os conhecimentos, ou seja, suas concepções pedagógicas. Os resultados apontam que a lógica das competências corresponde a uma tendência nos direcionamentos políticos e pedagógicos de negação dos conhecimentos científicos e culturais, e do papel da escola como responsável pela distribuição, o mais igualmente possível, dos conhecimentos sistematizados.

Palavras-chave: Políticas educacionais. Avaliações externas. Competências.

\begin{abstract}
This article presents reflections on the Brazilian policies for external evaluation with the aim to question the relevance of the emphasis that has been given to the different skills. Thereunto, we analyze the goals, the basis and the references of Brazilian main basic education test (Prova Brasi) and the SENNA Project, relating them to the new capital requirements and directions of international organizations from the 1990s. According to the analysis, initially, external evaluations focused on the amount of knowledge obtained, and later began to be guided by the model of different types of skills, influencing the way teachers assess and handle knowledge, that is their pedagogical conceptions. The results show that the logic of competences corresponds to a trend in political and pedagogical directions of denial of scientific and cultural knowledge, and of the school role as responsible for the distribution, as equally as possible, of systematized knowledge.
\end{abstract}

Keywords: Educational policies. External evaluations. Competences.

\footnotetext{
* Professora da Universidade Estadual de Maringá (UEM). E-mail: <elmajulia@hotmail.com>.

** Professora da Rede Municipal de Cianorte. Mestre em Educação pela UEM. E-mail: <janerigoldi@hotmail.com>.
} 
Resumen: Este artículo presenta reflexiones sobre la política brasileña de evaluación externa, con el objetivo de cuestionar la pertinencia del énfasis que se ha dado a las habilidades. Para ello, se analizan los objetivos, la justificación y las bases de referencia de la Prueba Brasil y Proyecto SENNA, en relación con los nuevos requisitos de capital y las direcciones de las organizaciones internacionales a partir de los años de 1990. De acuerdo con el análisis, en principio, las evaluaciones externas tenían perspectiva en el contenido, y posteriormente comenzó a ser guiada por el modelo de competencias, que influyen en la forma en que los maestros evalúan y cómo poner en práctica los conocimientos; es decir, sus concepciones pedagógicas. Los resultados muestran que la lógica de la competencia corresponde a una tendencia en direcciones políticas y pedagógicas de la negación del conocimiento científico y cultural, y el papel de la escuela como responsable de la distribución, como también es posible, de conocimiento sistematizado.

Palabras-clave: Políticas educativas. Evaluaciones externas. Habilidades.

\section{Introdução}

As avaliações externas têm se tornado cada vez mais presentes, seja nos encaminhamentos das políticas públicas para a educação, seja no debate educacional brasileiro. Tais avaliações têm sido empregadas pelos governos para traçar políticas educativas, projetos e programas que visam a melhorias, para oferecer informações à comunidade escolar sobre o desempenho dos alunos e para acompanhar, controlar e monitorar a qualidade da educação oferecida, bem como para buscar soluções para os possíveis déficits educacionais (BRASIL, 2013). Isso significa que tanto podem ser um elemento de regulação por parte do Estado, quanto um meio de prestação de contas à comunidade sobre projetos e resultados obtidos pelos alunos, considerando que o modelo político adotado é fundamentado no princípio de responsabilização e descentralização (CARVALHO, 2009).

No debate travado por educadores e especialistas, de um lado estão aqueles que de fendem as avaliações externas e destacam a relevância para medir a qualidade da educação pública (ARAÚJO; LUZIO, 2005; LE GRAND, 2010); de outro, os que lhes fazem severas críticas e as consideram instrumentos políticos de responsabilização (accountability) ${ }^{1}$ (FREITAS, 2007; AFONSO, 2009; SHIROMA; EVANGELISTA, 2011), já que, baseadas na lógica de mercado, elas fazem o controle administrativo dos sistemas de ensino e das escolas, e estimulam a comparação de resultados acadêmicos e competição entre instituições escolares.

De nossa parte, consideramos que as avaliações externas tornaram-se instrumentos socialmente aceitos, sinônimos de qualidade educacional. Desde 1990, o Estado brasileiro tem concentrado esforços para a construção de um consenso em relação a elas. Sua ampla aceitação permite afirmar que foi construído, também, um caminho para a implantação de novos instrumentos de avaliação, a exemplo do Projeto SENNA (Social and Emotional or Non-cognitive Nation wide Assessment ${ }^{2}$ ), cujo propósito é avaliar traços da personalidade. Este aspecto coloca a

\footnotetext{
${ }^{1} \mathrm{O}$ termo accountability tem um significado próximo à responsabilização ou prestação de contas. A avaliação é pedra angular das políticas educativas e práticas pedagógicas contemporâneas por contribuir para selecionar, classificar e responsabilizar, certificar, propor melhorias, mas, principalmente, por ser um exercício de autoridade (AFONSO, 2009).

2 SENNA é uma sigla inglesa que significa Avaliação Nacional Não-cognitiva ou Socioemocional (PRIMI; SANTOS, 2014). Esse modelo avaliativo, o próprio nome já enfatiza, está pautado em competências não cognitivas ou socioemocionais como, por exemplo, estabilidade emocional; conscienciosidade; extroversão; amabilidade e abertura a novas experiências, e está sendo formulado pelo Instituto Ayrton Senna, que conta com diversas parcerias com organizações internacionais e com o Ministério da Educação (MEC). Essa organização sem fins lucrativos integra, desde 2004, a rede de cátedras da Organização das Nações Unidas para a Educação, a Ciência e a Cultura (UNESCO), e realiza estudos na área de formação docente, avaliação e pedagogia para embasar políticas públicas por
}

Práxis Educativa, Ponta Grossa, p. 775-794, v. 11, n. 3, set./dez. 2016 Disponível em: <http://www.revistas2.uepg.br/index.php/praxiseducativa> 
necessidade de aprofundar reflexões sobre os processos de reformas educacionais, nos quais as avaliações apresentam-se como ação central. Na expectativa de contribuir para o debate, buscamos analisar as avaliações externas, particularmente a Prova Brasil e Projeto SENNA, relacionando-as às mudanças políticas, econômicas e sociais vivenciadas na sociedade atual, com o objetivo de compreender por que elas passam a se pautar na lógica do modelo de competências.

Em nossa análise, procuramos destacar que as avaliações externas correspondem a um dos pontos estratégicos no processo de reformas educacionais a partir dos anos de 1990: “[...] por trás das escolhas de uma técnica de avaliação, manifestam-se opções educativas e tentativas de interferir no processo de construção dos conhecimentos entre os alunos, nos próprios conhecimentos e na maneira como o docente os operacionaliza" (ROPÉ; TANGUY, 1997, p. 21). Em outras palavras, entendemos que as modalidades e técnicas de avaliação não são neutras; pelo contrário, revestem-se de significações e são permeadas por intencionalidades políticas e ideológicas.

Considerando a não neutralidade das técnicas de avaliação e sua capacidade de interferir na prática pedagógica, em um primeiro momento discutimos o conceito de competências, desvelando sua retórica e seus vínculos com os direcionamentos das organizações internacionais a partir dos anos de 1990. Em um segundo momento descreveremos as características da Prova Brasil, considerando as alterações que ocorreram no Sistema de Avaliação da Educação Básica $(\mathrm{SAEB})^{3}$ em 1997, quando o sistema, secundarizando a avaliação pautada nos conteúdos, aderiu a avaliações de competências cognitivas. Em seguida, refletiremos sobre a avaliação de competências socioemocionais elaborada pelo Projeto SENNA, destacando, a partir de suas matrizes de referência, seus objetivos e fundamentos em relação às novas exigências do mundo produtivo, com base no modelo flexível. Por fim, teceremos algumas considerações sobre os desdobramentos sociais e educacionais das avaliações externas pautadas nas competências.

\section{A avaliação de competências nos encaminhamentos da atual politica educacional}

A Prova Brasil e a avaliação realizada pelo Projeto SENNA declaram avaliar conjuntos de competências: a primeira relacionada aos aspectos cognitivos; a segunda, às competências socioemocionais.

Em geral, na gestão do mundo produtivo, o termo competência associa-se à “[...] capacidade em realizar uma tarefa com a ajuda de ferramentas materiais e/ou instrumentos intelectuais" (LAVAL, 2004, p. 55). Dessa maneira, designa um conhecimento inseparável da ação ou do saber prático. No campo educacional, esse termo é herdeiro de um campo de discussões ambíguo e polissêmico. A prática avaliativa, ao expressar tensões, conflitos e contradições próprios da sociedade, revela ser portadora de concepções de mundo e compromissos com projetos sociais distintos. Neste sentido, o conceito de competências possui um

cerca de vinte anos. Para realizar essa grande variedade de trabalhos, o Instituto conta com recursos financeiros próprios e doações de pessoas físicas e empresas privadas. Hoje atende aproximadamente 75 mil professores, 2 milhões de alunos em 1200 municípios (PRIMI; SANTOS, 2014).

${ }^{3}$ O Sistema de Avaliação da Educação Básica (SAEB), atualmente, centra-se em três avaliações: Avaliação Nacional da Educação Básica (ANEB); Avaliação Nacional do Rendimento Escolar (ANRESC), popularmente conhecida por Prova Brasil, e Avaliação Nacional da Alfabetização (ANA).

Práxis Educativa, Ponta Grossa, p. 775-794, v. 11, n. 3, set./dez. 2016 Disponível em: <http://www.revistas2.uepg.br/index.php/praxiseducativa> 
[...] caráter ideológico [...] que precisa ser adequadamente discutido, através do estudo minucioso desta categoria em suas relações com o mundo do trabalho. Esta necessidade se reforça pela ambiguidade, típica das ideologias, que tem revestido esta discussão no campo da educação. (KUENZER, 2001, p. 4).

Segundo Dias Sobrinho (2003), o que e como se avalia são marcados por opções de ordem metodológica e epistemológica que, por sua vez, resultam de disputas políticas e ideológicas. Por isso, ao analisar a política de avaliação educacional, devemos considerar que as palavras não são carregadas apenas de sentidos, mas em decorrência das mudanças sociais, também assumem novos significados. Em geral, a ressignificação é parte da estratégia de "[...] assegurar a obediência e resignação públicas, o pragmático vocabulário se faz necessário para erradicar o que é considerado obsoleto e criar novas formas de controle e regulações sociais". Ou seja, a finalidade é "alcançar o consenso [...]" (MORAES, 2001, p. 14, passim).

Para alcançar o consenso em relação à aceitação da noção das competências, destacamos a intensa atuação de organizações internacionais ${ }^{4}$, dentre as quais o Banco Mundial (BM), a Organização para Cooperação e Desenvolvimento Econômico (OCDE) e a Organização das Nações Unidas para Educação, Ciência e Cultura (UNESCO). Segundo Ianni (1997), tais organizações podem ser entendidas como grandes blocos de poder, cujo interesse é utilizar a educação e, consequentemente, as avaliações externas como instrumentos de controle dos sistemas e, conjuntamente, formar um perfil de sujeito almejado pela sociedade global.

Os documentos formulados por essas organizações têm sido direcionadores das ações políticas relacionadas à educação não apenas no Brasil, mas no mundo, especialmente a partir de $1990^{5}$. Segundo Afonso (2009), a avaliação é valorizada por assegurar formas mais sofisticadas de regulação e de controle por parte do Estado.

A maioria desses documentos reafirma a importância da avaliação, bem como a necessidade de constituição de sistemas nacionais de avaliação. Podemos identificar essa influência no Artigo 5 $5^{\circ}$, da Portaria n ${ }^{\circ}$ 1795, de 27 de dezembro de 1994, que institui oficialmente o Sistema de Avaliação da Educação Básica (SAEB):

O Ministério da Educação e do Desporto, em colaboração com as Secretarias de Educação, assegurará os meios necessários ao estabelecimento de amplos mecanismos de cooperação e intercâmbio técnico e institucional com organismos nacionais, estrangeiros e internacionais visando ao desenvolvimento do Sistema. (BRASIL, 1994, p. 20768).

Portanto, seguindo as orientações internacionais, a avaliação emerge como eixo central para orientar as reformas educacionais brasileiras (BRASIL, 1994), induzindo o que deve ser ensinado, o que deve ser aprendido e como esse processo deve ocorrer. Esse aspecto pode ser observado nas indicações do Banco Mundial:

Para criar conhecimentos sobre a reforma e intervenções na educação, o Banco Mundial fornecerá: avaliação do sistema e ferramentas de comparação, juntamente com dados de informação, para avaliar a capacidade de um sistema educacional para melhorar os resultados de aprendizagem; avaliações da aprendizagem e realização de objetivos que abranjam as competências básicas de leitura e aritmética, bem como outras aptidões incluindo

\footnotetext{
${ }^{4}$ As orientações dessas organizações contam com a aceitação das elites dirigentes, pelas quais são consensualmente assumidas, por isso o Brasil não pode ser visto apenas como um ator coadjuvante, ou uma vítima nesse processo, mas atua como um dos agentes principais de formulação, execução e apoio às políticas dessas organizações (SILVA, 2002).

${ }^{5}$ Dale (2004) refere-se a uma agenda globalmente estruturada para educaşão, que contribui para que muitos países, apesar de suas especificidades, tenham em sua pauta de reformas pontos muito semelhantes.
}

Práxis Educativa, Ponta Grossa, p. 775-794, v. 11, n. 3, set./dez. 2016 Disponível em: <http://www.revistas2.uepg.br/index.php/praxiseducativa> 
pensamento crítico, solução de problemas e aptidões para trabalhar em equipa [sic]. (BANCO MUNDIAL, 2011, p. 8, grifos nossos).

Os documentos também direcionam a prática educativa de modo que as competências passem a ser cada vez mais valorizadas. O Relatório Delors, considerado um dos documentos mais influentes nas recentes reformas educacionais, por exemplo, orienta o processo educativo a formar competências de ordem afetiva e cognitiva.

\begin{abstract}
Definindo as competências cognitivas e afetivas que devem ser desenvolvidas, assim como o corpo de conhecimentos essenciais que devem ser transmitidos pela educação básica, os especialistas em educação podem fazer com que todas as crianças, tanto nos países em desenvolvimento como nos países industrializados, adquiram um mínimo de competências sobre os principais domínios das aptidões cognitivas. (DELORS, 1998, p. 126).
\end{abstract}

Alinhados a essas orientações, a Prova Brasil (BRASIL, 2008) e o Projeto SENNA (PRIMI, SANTOS, 2014; INSTITUTO AYRTON SENNA - IAS; UNESCO, ([2013]) têm como fim declarado avaliar conjuntos de competências. A Prova Brasil busca avaliar as chamadas competências básicas de cálculo e leitura, e o Projeto SENNA, as competências socioemocionais relacionadas à personalidade, conforme trataremos adiante.

Para compreender os novos direcionamentos (BRASIL, 2008; 2013), é importante destacar algumas alterações no sistema produtivo, no qual a noção de competências tem origem. O modelo de gestão pautado em competências surge como resposta à crise de 1970, cuja causa, dentre outras, é o esgotamento do modelo de organização taylorista/fordista. $\mathrm{Na}$ busca por aumentar a produtividade e a competitividade das empresas, esse modelo, caracterizado pela produção em série, homogeneizada, com baixo desenvolvimento tecnológico e autoritário controle central, foi substituído pelo modelo toyotista, sinônimo de produção flexível, diversificada e enxuta, pautada no alto desenvolvimento tecnológico e organizacional, em poderes difusos e em modelos participativos de gestão.

Essas mudanças passam a exigir um novo perfil de trabalhador. Este deixa de realizar atividades prescritas e rotineiras para exercer tarefas diversificadas, o que implica que deve ser flexível e apresentar um coquetel de competências (DELORS, 1998), ou seja, capacidades para se mobilizar diante de situações imprevistas.

A ideologia da gestão por competências, com foco na reorganização da produção, contou com a participação de estudiosos norte-americanos e anglo-saxões, dentre os quais alguns psicólogos, como McClelland, Skinner e Bloom e seu grupo, que contribuíram para a formulação de modelos avaliativos de pessoas e seus desempenhos (RAMOS, 2011).

Nos anos de 1980, esses estudos passaram a ser utilizados em setores de recursos humanos das empresas para selecionar, recrutar e formar trabalhadores com o perfil profissional desejado. Foi, porém, a partir dos anos de 1990 que eles ganharam maior notoriedade, passando a sofrer influência da escola francesa, cujos representantes, como Le Bortef (2006) e Phillipe Zarifian (2003), acrescentaram a ideia de que é preciso mobilizar conhecimentos, valores e atitudes para agir.

Em face das novas demandas do sistema produtivo, as empresas passaram a contratar os serviços de consultores para a realização de inovações organizacionais, com base no modelo de competências.

A ideologia das competências, porém, extrapolou o mundo produtivo e chegou às escolas, ganhando status de pedagogia e tornando-se referência para a formulação de currículos, 
diretrizes, materiais didáticos, teorias educacionais (RAMOS, 2011) e matrizes de avaliação, conforme veremos a seguir.

\section{Prova Brasil: avaliação de competências cognitivas}

Embora exista uma diversidade de avaliações externas ${ }^{6}$, priorizaremos, em nossa análise, a Avaliação Nacional do Rendimento Escolar (ANRESC) do Ensino Fundamental, a qual, a partir de 2007, passou a ser denominada de Prova Brasil. Seu objetivo é avaliar bianualmente os sistemas de ensino público, gerando dados por escola, município, estado e no país. Portanto, diz respeito ao sistema de ensino e a cada unidade escolar (BRASIL, 2013). Nos termos da Portaria $n^{\circ}$ 482, de 7 de julho de 2013, os objetivos declarados dessa avaliação são:

[...] contribuir para o desenvolvimento, em todos os níveis educativos, de uma cultura avaliativa que estimule a melhoria dos padrões de qualidade e equidade da educação brasileira e adequados controles sociais de seus resultados; [...] oportunizar informações sistemáticas sobre as unidades escolares [...]. (BRASIL, 2013, p. 17).

A Prova Brasil ${ }^{7}$ pode ser considerada uma das avaliações mais conhecidas pela sociedade, já que apresenta índices por escola, periodicamente divulgados. Em 2005, o Sistema de Avaliação da Educação Básica (SAEB) abandonou o modelo amostral, por meio do qual pode aumentar sua abrangência, seu impacto social e, principalmente, a quantidade de alunos avaliados.

Para a realização de uma avaliação com amplitude nacional, tornou-se necessária a construção de uma matriz de referência: o "[...] referencial curricular do que será avaliado em cada disciplina ou série, informando as competências e habilidades esperadas dos alunos" (BRASIL, 2008a, p. 17). Ou seja, essa avaliação não engloba todo o currículo escolar, mas aspectos que associam competências e conteúdos considerados básicos:

[...] estudantes da $4^{a}$ série $/ 5^{\circ}$ ano e $8^{a}$ série $/ 9^{\circ}$ ano do Ensino Fundamental; - Avalia as escolas da rede pública localizadas em área urbana e rural; - A avaliação é censitária: todos os estudantes das séries/anos avaliados, de todas as escolas públicas urbanas e rurais do Brasil com mais de 20 alunos matriculados na série/ano devem fazer a prova; - Avalia habilidades em Língua Portuguesa (foco em leitura) e Matemática (foco na resolução de problemas); - A partir de 2013 também serão realizadas provas de Ciências (somente para a $8^{\mathrm{a}}$ série $/ 9^{\circ}$ ano do Ensino Fundamental). (BRASIL, 2011, p. 01).

Os testes padronizados da Prova Brasil são compostos por quatro blocos de onze questões: dois de Língua Portuguesa e dois de Matemática. Os alunos respondem, também, a questionários socioeconômicos, cujas questões visam a analisar relações entre condições de vida que podem influenciar o desempenho acadêmico. Um dos aspectos inovadores dessa avaliação é que, a partir de 1997, o SAEB passou a formular instrumentos que não priorizam a memorização de conteúdos, ao passo que, nos ciclos de 1990, 1993 e 1995, esse aspecto fundamentou a elaboração das matrizes curriculares de referência para aferir o desempenho educacional dos alunos. Nesses ciclos, foram avaliados conteúdos que exigiam "[...] a memorização do conteúdo, outras, a compreensão do que era solicitado e, em alguns casos, a resolução de um problema ou situação por meio da aplicação de algo já aprendido" (BRASIL, 1995, p. 15). Ao deixar de se

\footnotetext{
${ }^{6}$ Além da Prova Brasil, outros instrumentos avaliativos, como exames vestibulares, concursos, o Exame Nacional do Ensino Médio (ENEM) e o Programa Internacional de Avaliação de Estudantes (PISA) valorizam a avaliação de competências.

7 A Prova Brasil foi criada pela Portaria Ministerial no 931, de 21 de março de 2005. Este documento estabelece que o planejamento do que é avaliado e as metodologias utilizadas são de responsabilidade do INEP, por meio da DAEB, que define "[...] os instrumentos a serem utilizados, as séries e disciplinas, bem como as competências e habilidades a serem avaliadas [...]” (BRASIL, 2005, p. 17).
}

Práxis Educativa, Ponta Grossa, p. 775-794, v. 11, n. 3, set./dez. 2016 Disponível em: <http://www.revistas2.uepg.br/index.php/praxiseducativa> 
pautar na perspectiva conteudista, para a qual era preciso evocar conceitos universais anteriormente apreendidos, as avaliações passaram a pautar-se nas competências cognitivas (BONAMINO; FRANCO, 1999) e nas habilidades que os alunos deveriam dominar em cada série avaliada. Essas competências eram relacionadas à "[...] capacidade de interpretar, refletir, raciocinar, pensar abstratamente, assimilar ideias complexas, resolver problemas e generalizar aprendizagens [...]" (IAS; UNESCO, [2013], p.9).

De acordo com Bonamino (2002), em 1997, grupos organizados por Maria Inês Fini optaram pela formulação de matrizes de competências para as avaliações do SAEB. Tais grupos objetivavam disseminar a perspectiva das competências, em consonância com as modificações curriculares que ocorreram com a formulação dos Parâmetros Curriculares Nacionais (PCN), Diretrizes Curriculares Nacionais (DCN), entre outros documentos orientadores. Vemos que, nesse momento, a lógica era ressignificar conteúdos, atribuindo-lhes novas dimensões, ou seja, foi incluída, como objeto de aprendizagem escolar, a formação de normas, atitudes e valores (BRASIL, 1997).

Podemos inferir que, subjacentes aos instrumentos de avaliação, há concepções epistemológicas sobre o que ensinar e como fazê-lo (DIAS SOBRINHO, 2003). Assim, os grupos que optaram por avaliar competências orientaram-se pela perspectiva construtivista ${ }^{8}$ (BONAMINO, 2002). Em decorrência dessa opção observamos que, a partir desse momento, o enfoque sobre os conteúdos ganharam novas dimensões e adjetivações, descritas como conceituais, procedimentais e atitudinais. Para a elaboração dos itens da Prova Brasil, "[...] buscou-se uma associação entre conteúdos de aprendizagem e as competências utilizadas no processo de construção do conhecimento" (BRASIL, 2008, p. 17).

A dimensão atitudinal relacionada à formação de valores ganhou relevância na formulação das matrizes de referência pautadas em competências cognitivas e habilidades instrumentais (BRASIL, 1997). Nestes termos, também a prática educativa sofreu modificações: a escola não deveria mais ensinar conceitos sem considerar a utilidade prática e a formação de novas atitudes.

$\mathrm{Na}$ área de Língua Portuguesa, para justificar a reforma, usaram-se argumentos de que não fazia sentido avaliar conhecimentos teóricos, enciclopédicos. Para diagnosticar o desempenho linguístico dos alunos, no cotidiano, era preciso formular uma matriz de referência que fosse capaz de valorizar "[...] conhecimentos operacionais ao invés de elencar conhecimentos enciclopédicos” (BRASIL, 1998, p. 12).

Em sintonia com a pedagogia das competências, em relação à avaliação de Língua Portuguesa, declarava-se:

As abordagens tradicionais de ensino da Língua Portuguesa lidavam com concepção instrumental de que a linguagem seria uma expressão fiel do nosso pensamento, apenas por meio de um conjunto de regras que deveriam ser rigorosamente seguidas. Isso fez com que o ensino do idioma materno se tornasse uma prática mecânica, calcada na memorização (listas de coletivos, adjetivos, conjunção de verbos, regras de concordância, pontuação, entre outras) na exploração da metalinguagem (classificação de termos e de funções). (BRASIL, 2008, p. 20-21, grifos no original).

De acordo com o documento PDE: Plano de Desenvolvimento da Educação: Prova Brasil: ensino fundamental: matrizes de referência, tópicos e descritores, o referencial teórico da perspectiva de

\footnotetext{
8 Nessa concepção biológica de desenvolvimento, o aluno constrói esquemas para resolver conflitos, os quais, entendidos como recursos do pensamento humano, são denominados competências. O conhecimento não resulta da apropriação de uma realidade objetiva, mas da construção do sujeito para se adaptar ao meio. Por isso, sua definição é construtivismo, e a pedagogia das competências é uma das dimensões desta corrente (RAMOS, 2011).
}

Práxis Educativa, Ponta Grossa, p. 775-794, v. 11, n. 3, set./dez. 2016 Disponível em: <http://www.revistas2.uepg.br/index.php/praxiseducativa> 
competências da Prova Brasil segue a vertente teórica desenvolvida por Philippe Perrenoud. No documento, é declarado que os "[...] itens do SAEB e da Prova Brasil, [...] [apresentam] uma associação entre os conteúdos da aprendizagem e as competências utilizadas [...] na perspectiva de Perrenoud", segundo o qual "[...] as competências cognitivas podem ser entendidas como diferentes modalidades estruturais da inteligência que compreendem determinadas operações que o sujeito utiliza para estabelecer relações com e entre objetos físicos, conceitos, situações, fenômenos e pessoas" (BRASIL, 2008, p. 18, passim).

Perrenoud é autor de expressivo reconhecimento no Brasil, e tem publicado livros que tratam de temáticas educacionais variadas, dentre as quais a da avaliação. Ao posicionar-se favoravelmente às reformas, ele defende a necessidade de mudança nas práticas tradicionais de avaliação. De sua perspectiva, é preciso

[...] [soltar] as amarras da avaliação tradicional, [para] facilita $[r]$ a transformação das práticas de ensino em pedagogias mais abertas, ativas, individualizadas, abrindo mais espaço à descoberta, à pesquisa, aos projetos, honrando mais os objetivos de alto nível tais como aprender a aprender, a criar, a imaginar, a comunicar-se. (PERRENOUD, 1999, p. 66, grifos do autor).

Ao propor inovações para modificar a escola, o autor tece severas críticas aos currículos escolares, que tendem a privilegiar conteúdos desgastados, ultrapassados e desconectados da realidade, bem como à forma como a escola avalia. Em sua interpretação, as escolas e os professores

[...] tende[m] a privilegiar atividades fechadas, estruturadas, desgastadas, que podem ser retomadas no quadro de uma avaliação clássica; [...] O sistema clássico de avaliação força os professores a preferir os conhecimentos isoláveis e cifráveis às competências de alto nivel (raciocínio, comunicação) [...]. (PERRENOUD, 1999, p. 66, grifos do autor).

Portanto, segundo o autor, as escolas deveriam voltar-se ao que é útil e atrativo, valorizar os conhecimentos transferíveis e as competências utilizáveis. Em suas proposições, a pedagogia não deve estar voltada apenas à aprendizagem de conceitos científicos, pois estes, embora tenham status de objetivos universais ou mais legítimos, têm pouca significância para a resolução de situações cotidianas. Assim, a aprendizagem deve valorizar os saberes do "senso comum" (PERRENOUD, 2001, p. 154) porque

[...] o domínio dos saberes eruditos, por mais amplos e voltados para a ação que sejam, não são suficientes para garantir as competências, que é preciso levar em conta o habitus chamado de ajuda, arte, maneira, aspecto, inteligência-e os saberes 'não-eruditos', mesmo que sejam especializados, construídos gradualmente por cada um ou transmitidos pelo ambiente profissional. (PERRENOUD, 2001, p. 158, grifos do autor).

Nesses termos, embora a pedagogia das competências não negue o conhecimento e a reflexão, o sentido da competência está relacionado a saber responder a um problema em tempo hábil, ou seja, está relacionado ao agir. Assim, a formação direcionada por essa pedagogia não se ampara em conhecimentos objetivos, mas em uma formação que parte da ação do sujeito, que é entendido como capaz de construir, de maneira subjetiva, a partir da sua ação, seus próprios conhecimentos.

Apesar de as reflexões de Perrenoud (1999) estarem voltadas para a avaliação escolar e não para as avaliações externas, seu pensamento influenciou a formulação de avaliações como a Prova Brasil. Isto porque havia uma compreensão de que, para que ocorressem mudanças nas práticas pedagógicas e para que a pedagogia das competências fosse incorporada ao trabalho escolar, a forma de avaliação deveria ser alterada (PERRENOUD, 1999).

Práxis Educativa, Ponta Grossa, p. 775-794, v. 11, n. 3, set./dez. 2016 Disponível em: < http://www.revistas2.uepg.br/index.php/praxiseducativa > 
$\mathrm{Na}$ sistemática de estruturação das questões da Prova Brasil para Língua Portuguesa, não são elencadas questões de análise ortográfica ou gramatical, nem mesmo de análise sintática. Em Matemática, a maioria das questões é voltada para a resolução de problemas que privilegiam mecanismos de raciocínio lógico, mais do que propriamente a retomada de conceitos anteriormente aprendidos (BRASIL, 2008). Um exemplo pode ser observado na questão a seguir, na qual podemos visualizar como os preceitos da pedagogia das competências se materializam no novo modelo de avaliação:

Figura 1 - Exemplo de questão - Prova Brasil (2008)

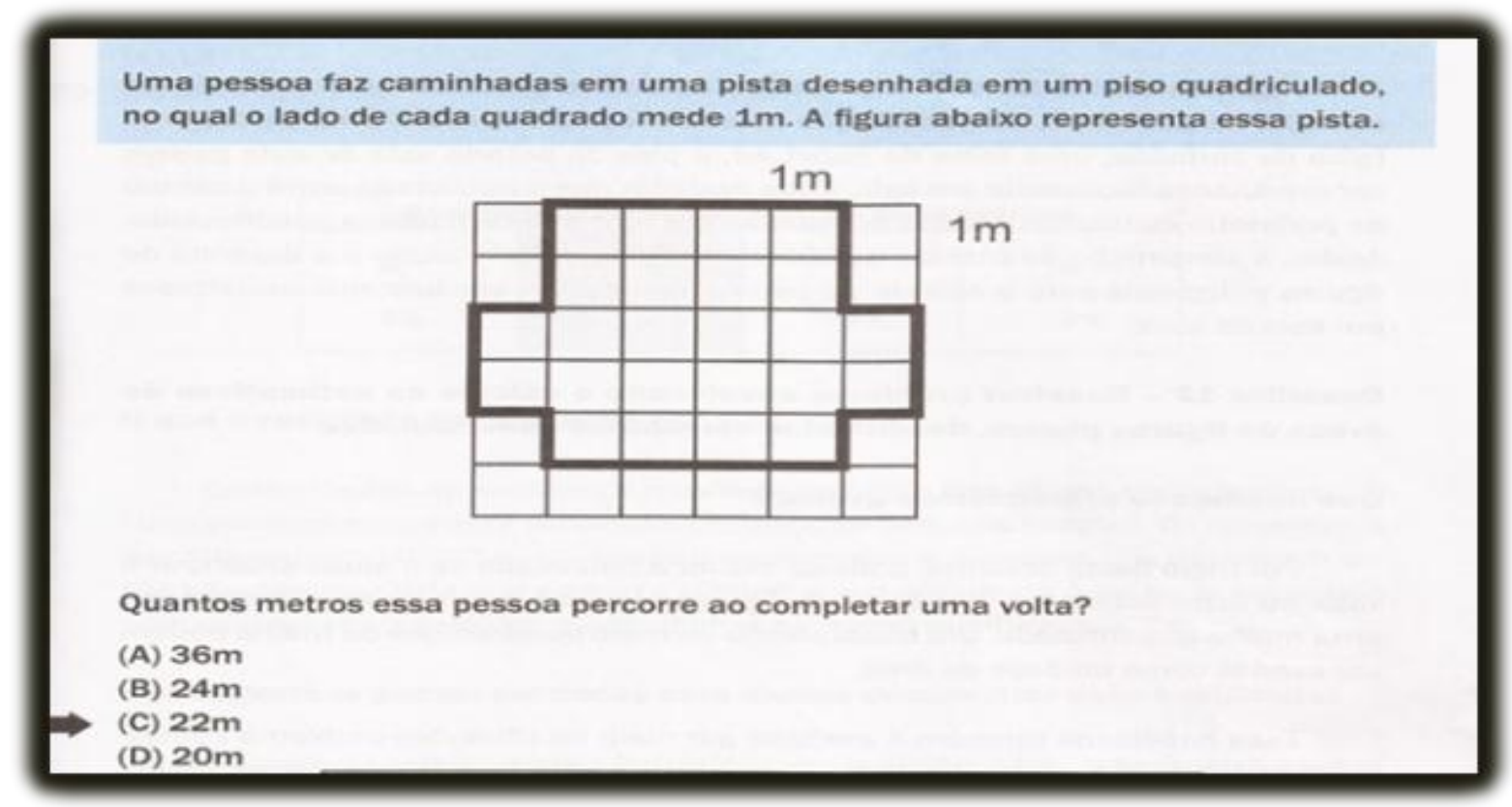

Fonte: Brasil (2008, p. 127).

De acordo com o Descritor 11, que serve de referência para a seleção dos itens que devem compor a elaboração da avaliação, esta questão, que implica a associação de conteúdos curriculares e operações mentais desenvolvidas pelo aluno, buscaria avaliar a habilidade de "Resolver problema envolvendo o cálculo de perímetro de figuras planas, desenhadas em malhas quadriculadas" (BRASIL, 2008, p. 126). No entanto, a ausência de referência ao conceito de perímetro revela que, em nome da contextualização e da necessidade de aproximar a atividade à linguagem do aluno, o conhecimento sistematizado foi diluído. Temos indícios de que o mais importante, nesse procedimento, é a avaliação da habilidade de raciocínio em situações novas, prescindindo, portanto, da retomada de conceitos anteriormente assimilados, ou da inteligência denominada fluida:

[...] a inteligência fluida (que prioriza o raciocínio) [...] refere-se à capacidade de processamento cognitivo, isto é, à capacidade geral de processar informações (por exemplo, relacionar idéias [sic] complexas, formar conceitos abstratos, derivar implicações lógicas a partir de regras gerais) ou às operações mentais realizadas quando se resolvem problemas relativamente novos, para os quais existem poucos conhecimentos previamente memorizados. (ACKERMAN, 1996; ACKERMAN; HEGGESTAD, 1997; ACKERMAN, KYLLONEN; ROBERTS, 1999 apud PRIMI et al., 2001, p. 157, grifos nossos).

Para resolver a questão acima apresentada, é possível que o aluno chegue à resposta correta apenas analisando a questão em si, sem necessariamente ter domínio do conceito de perímetro.

Práxis Educativa, Ponta Grossa, p. 775-794, v. 11, n. 3, set./dez. 2016 Disponível em: <http://www.revistas2.uepg.br/index.php/praxiseducativa> 
Considerando esses aspectos, entendemos que o SAEB popularizou avaliações externas no Brasil e, criando a almejada cultura avaliativa, abriu as portas para que novos formatos de avaliação pudessem emergir e se consolidar, como mostraremos a seguir.

\section{Projeto SENNA: avaliação de competências socioemocionais}

O sistema SENNA é a mais recente iniciativa de avaliação, representando o empreendimento de esforços para avaliar atributos da personalidade. Essa proposta, formulada com o "objetivo de subsidiar tanto as políticas públicas quanto as práticas pedagógicas" (IAS; UNESCO, [2013], p. 23), está sendo desenvolvida por meio de uma parceria firmada entre o Instituto Ayrton Senna (IAS), a OCDE, o Ministério da Educação (MEC) e o governo do Rio de Janeiro.

O projeto piloto, elaborado com o auxílio de especialistas estrangeiros, foi discutido inicialmente em um encontro denominado Education and Social Progress-Longitudinal Study Skill Dynamics, ocorrido em Washington, em junho de 2013 e cuja organização esteve a cargo da OCDE (PRIMI; SANTOS, 2014). Nesse evento foram formuladas orientações para que, em outubro de 2013, fosse iniciada a experiência pioneira de avaliação de aspectos relativos à personalidade.

Com o intuito de transformar a avaliação socioemocional em política pública, o primeiro instrumento avaliativo foi aplicado em 24.605 alunos da rede estadual do Rio de Janeiro, do $5^{\circ}$ ano do Ensino Fundamental, $1^{\circ}$ ano e $3^{\circ}$ anos do Ensino Médio. Esse modelo avaliativo é constituído por, aproximadamente, 70 a 100 questões, contando com um questionário socioeconômico.

No Relatório intitulado Desenvolvimento socioemocional e aprendizado escolar: uma proposta de mensuração para apoiar políticas públicas, de autoria de Ricardo Primi e Daniel Santos (2014), foram apresentados os resultados preliminares do projeto. Declaram os autores que, para atender aos objetivos da proposta, o instrumento de medição foi construído para ser barato e passível de ser utilizado em diferentes países e culturas (PRIMI; SANTOS, 2014).

De nosso ponto de vista, a nova proposta, cujo objetivo é avaliar atributos relacionados ao caráter e à personalidade, é bastante questionável, pois, além de buscar mensurar algo subjetivo, não parece capaz de diagnósticos consistentes. É questionável, ainda, por apontar para a "criação em escala planetária" de "programas cuidadosamente estruturados" (DELORS, 1998, p. 244) que, adaptados às exigências do capital flexível, procuram relacionar traços da personalidade e crescimento econômico e atuar sobre a subjetividade humana.

Essa avaliação difere de outras, como a Prova Brasil, cujo objetivo é avaliar competências básicas relacionadas à leitura interpretativa e à resolução de problemas ou capacidades acadêmicas. Para a elaboração da matriz de referência da avaliação, seus idealizadores embasaramse em cinco dimensões da personalidade humana, denominadas de Big Five: abertura a novas experiências; amabilidade; extroversão; conscienciosidade e estabilidade emocional (PRIMI; SANTOS, 2014). O modelo de classificação adotado reúne essas cinco dimensões e, para cada uma delas, "são descritas as competências abarcadas e, para cada uma das competências, as atitudes observáveis em sala” (IAS; UNESCO, [2013], p. 23).

Para ilustrar as matrizes de referência de competências socioemocionais, selecionamos um quadro no qual estão reunidas as dimensões que devem orientar a formulação do processo avaliativo e o planejamento das atividades pedagógicas pelos professores:

Práxis Educativa, Ponta Grossa, p. 775-794, v. 11, n. 3, set./dez. 2016 Disponível em: < http://www.revistas2.uepg.br/index.php/praxiseducativa > 
Quadro 1 - Matriz de avaliação de competências socioemocionais

\begin{tabular}{|l|l|l|l|l|l|}
\hline Dimensão & $\begin{array}{l}\text { Estabelecimento e } \\
\text { alcance de objetivos } \\
\text { (Conscienciosidade) }\end{array}$ & $\begin{array}{l}\text { Respeito e cuidado } \\
\text { pelos outros } \\
\text { (Amabilidade) }\end{array}$ & $\begin{array}{l}\text { Sociabilidade e } \\
\text { entusiasmo } \\
\text { (Extroversão) }\end{array}$ & $\begin{array}{l}\text { Abertura para o } \\
\text { novo (Abertura) }\end{array}$ & $\begin{array}{l}\text { Gestão das } \\
\text { emoções } \\
\text { (Estabilidade } \\
\text { emocional) }\end{array}$ \\
\hline Competência & $\begin{array}{l}\text { Ex.: } \\
\text { Responsabilidade }\end{array}$ & Ex.: Colaboração & $\begin{array}{l}\text { Ex.: } \\
\text { Comunicação }\end{array}$ & Ex.: Curiosidade & $\begin{array}{l}\text { Ex.: } \\
\text { Autocontrole }\end{array}$ \\
\hline Atitude & $\begin{array}{l}\text { Ex.: O aluno vai } \\
\text { preparado para as } \\
\text { aulas; permanece } \\
\text { comprometido com } \\
\text { seus objetivos, } \\
\text { mesmo que levem } \\
\text { muito tempo para } \\
\text { ser alcançados. }\end{array}$ & $\begin{array}{l}\text { Ex.: O aluno } \\
\text { encontra soluções } \\
\text { em meio a } \\
\text { conflitos com os } \\
\text { colegas; demonstra } \\
\text { respeito pelo } \\
\text { sentimento dos } \\
\text { outros. }\end{array}$ & $\begin{array}{l}\text { Ex.: O aluno } \\
\text { participa } \\
\text { ativamente; } \\
\text { encara as } \\
\text { atividades com } \\
\text { entusiasmo. }\end{array}$ & $\begin{array}{l}\text { Ex.: O aluno } \\
\text { demonstra } \\
\text { interesse em } \\
\text { aprender; faz } \\
\text { perguntas para } \\
\text { melhorar a } \\
\text { compreensão. }\end{array}$ & $\begin{array}{l}\text { Ex.: O aluno } \\
\text { calmo, mesmono } \\
\text { quando criticado } \\
\text { ou provocado. }\end{array}$ \\
\hline
\end{tabular}

Fonte: IAS - UNESCO ([2013], p. 23).

É pertinente destacar que essas cinco dimensões que descrevem a personalidade humana não são utilizadas apenas para a elaboração de avaliações externas aplicadas a estudantes; são também aplicadas em setores de recursos humanos das empresas, com a finalidade de oferecer, aos empregadores, uma visão das características comportamentais dos trabalhadores que almejam contratar (CENTRO..., [2013]).

O instrumento de avaliação de competências socioemocionais, formulado com base nessas competências, contém questões que exigem, dos alunos, uma autoavaliação de sua personalidade e de suas reações comportamentais em determinadas situações do cotidiano. Entretanto, com o intuito de desenvolver determinados traços de personalidade nos alunos, essa matriz de referência torna-se um instrumento de política educativa suscetível de modificar o perfil profissional dos professores, bem como as práticas pedagógicas e de gestão. É o que podemos observar no documento Competências socioemocionais: material de discussão.

A aplicação dessa avaliação só faz sentido em ambientes de aprendizagem nos quais são criadas as condições necessárias para a manifestação dessas atitudes, ou seja, ambientes nos quais as competências socioemocionais já estejam sendo intencionalmente desenvolvidas. (IAS; UNESCO, [2003], p. 27).

Tendo em vista que "a dimensão socioemocional é tão importante quanto à dimensão cognitiva para a formação de seres humanos" (IAS; UNESCO, [2013?], p. 21), dentre as diversas questões do modelo avaliativo de competências socioemocionais, selecionamos algumas que parecem mais pertinentes para ilustrar nossa discussão:

[...] 2- Perco a cabeça com facilidade [...] 4- Sou amável com quase todo mundo [...] 6Sou um aluno (a) cuidadoso (a) e dedicado (a) [...] 8- Eu sou carinhoso com meus colegas [...] 10- Tenho facilidade em perdoar. 11- Fico nervoso com facilidade [...] 13Eu me comporto gentilmente com os outros. 14- Não tenho paciência [...]17- Não ligo que os outros usem minhas coisas [...] 21- Gosto de colaborar com os outros [...] 24Sou calmo (a) e controlo bem meu estresse [...] 33- Começo bate-boca com os outros. 34- Sou uma pessoa feliz e ativa [...] 41- Sou obediente e faço o que me mandar [...] 46Gosto de conversar [...]. (PRIMI; SANTOS, 2014, p. 84-85).

Em face destas questões, os alunos devem assinalar alternativas que podem ter nada, pouco, mais ou menos, muito ou totalmente a ver com seus comportamentos. Assim, ao passo que as avaliações tradicionais buscavam aferir aspectos acadêmicos, que exigiam o domínio de conceitos para a resolução das questões, os instrumentos de avaliação de competências 
socioemocionais procuram mensurar aspectos como sociabilidade, responsabilidade, tolerância, persistência, resiliência, dentre outras. $\mathrm{O}$ argumento é o de que essas competências

[...] desempenham um papel importante quando indivíduos trabalham em equipe,
atingem metas e lidam com emoções. E são importantes em todos os estágios da vida.
Por exemplo, controlar emoções pode contribuir para evitar que crianças interrompam
a aula ou percam um amigo. A mesma competência pode ajudar a impedir que um
adolescente abandone a escola, use drogas ou pratique sexo desprotegido. Estudos
empíricos sugerem que conscienciosidade, sociabilidade e estabilidade emocional estão entre as mais
importantes competências socioemocionais cujo desenvolvimento beneficiaria crianças, jovens e
sociedades em geral. (FÓRUM INTERNACIONAL..., 2014a, p. 3, grifos nossos).

Os defensores dessa proposta de avaliação tecem críticas às avaliações cognitivas pautadas nas competências relacionadas ao letramento, ao numeramento e aos diversos conteúdos disciplinares, afirmando que elas são incapazes de avaliar o homem em sua plenitude. Alegam estar empenhados em desenvolver métricas e taxionomias que contribuam para o que denominam de modernização da educação do país, cujo objetivo seria promover aprendizagens para desenvolver, nos alunos, os comportamentos requeridos pelo mundo contemporâneo.

De acordo com Primi e Santos (2014), o Relatório Delors, publicado pela UNESCO em 1996, teve um papel fundamental na inauguração do debate sobre a formação de competências socioemocionais. Analisando o referido documento, identificamos os apelos para a superação de conteúdos tradicionais e a ênfase na necessidade de ressignificação do papel da escola:

É por isso urgente empreender uma revolução criativa das nossas políticas educativas e de comunicação. Devem criar-se, à escala planetária, programas cuidadosamente estruturados, baseados, sem ambigüidade [sic], na idéia [sic] de que a sobrevivência da humanidade depende do desenvolvimento de uma consciência mundialista capaz de criatividade e compaixão. A dimensão espiritual deve estar no centro da nossa nova reflexão sobre educação. (DELORS, 1998, p. 244).

Em 2014, entre os dias 24 e 25 de março, no Brasil, na cidade de São Paulo, foi realizado um grande evento, intitulado Fórum Internacional de Políticas Públicas: Educar para as Competências do Século 21. Reunindo representantes de diversas regiões do mundo ${ }^{9}$, o Fórum teve como propósito fomentar o debate, apresentar experiências e firmar compromissos para a constituição de instrumentos, estudos e bancos de dados acerca das competências da população. A questão central, proposta aos governos presentes, era pensar políticas capazes de moldar comportamentos desejáveis e, segundo seus defensores, de gerar benefícios de ordem econômica, social e individual (FÓRUM INTERNACIONAL..., 2014a).

Destacamos que a OCDE tem ocupado um papel de destaque no direcionamento das avaliações e estudos sobre as competências socioemocionais. No Fórum, com a finalidade de consolidar a proposta como política pública mundial, desde a Educação Infantil até o Ensino Médio, seus organizadores comprometeram-se a oferecer apoio financeiro e técnico, criar bancos de dados, arquivos e pesquisas sobre a temática. Os países, por sua vez, comprometeram-se a:

[...] fortalecer a colaboração entre diferentes áreas de políticas públicas, assim como entre diferentes atores como pais, professores, administradores de escolas e gestores para garantir a coerência nas diretrizes e práticas para o desenvolvimento de competências e garantir apoio mútuo entre escolas, famílias e comunidade. Para isso, é preciso elevar o nível de informação a que pais e professores têm acesso em relação aos níveis (e à sua mudança) de competências socioemocionais das crianças; daí a relevância

\footnotetext{
9 Participaram do Fórum autoridades de países de diversas regiões do mundo, dentre eles: Argentina; Brasil; Colômbia; Coreia; Equador; Estados Unidos; Letônia; México; Noruega; Paraguai; Peru; Portugal; Suécia e Uruguai (FÓRUM INTERNACIONAL..., 2014b).
}

Práxis Educativa, Ponta Grossa, p. 775-794, v. 11, n. 3, set./dez. 2016 Disponível em: <http://www.revistas2.uepg.br/index.php/praxiseducativa> 
de medir essas competências de forma regular e precisa. (FÓRUM INTERNACIONAL..., 2014b, p. 3-4).

$\mathrm{Na}$ ocasião, os representantes do Estado brasileiro, especialmente do Ministério da Educação (MEC) e do Instituto Nacional de Estudos e Pesquisas Educacionais (INEP) manifestaram-se favoráveis a essa proposta de avaliação. Nessa mesma direção, a Coordenação de Aperfeiçoamento de Pessoal de Nível Superior (Capes) e o Instituto Ayrton Senna assinaram um termo de cooperação para incentivar pesquisas sobre o desenvolvimento e o papel das habilidades socioemocionais no ensino. $\mathrm{O}$ acordo firmado resultou na criação do Programa de Formação de Pesquisadores e Professores no Campo das Competências Socioemocionais, por meio do Edital $n^{\circ}$ 44/2014, que prevê a destinação de bolsas para o fomento da produção acadêmica e da formação de recursos humanos (BRASIL, 2014).

Verificamos, por meio de medidas como essas, que o Estado brasileiro busca incentivar e divulgar a ideia de avaliar e trabalhar com as dimensões do Big Five como parte do currículo, de modo que, nos encaminhamentos das atuais políticas educacionais, os aspectos comportamentais parecem merecer maior atenção do que a apropriação de conceitos sistematizados.

De nossa perspectiva, com essa nova lógica avaliativa, almeja-se formar um sujeito que saiba mobilizar comportamentos, valores e atitudes nos quadrantes da sociedade global, seja como trabalhador flexível, multifuncional, empreendedor e competitivo, seja como alguém capaz de lidar com o desemprego e o subemprego diante da instabilidade no mundo do trabalho, seja ainda como um cidadão ativo, responsável, colaborativo ou altruísta, como parte constituinte da proposta de uma nova sociabilidade (MARTINS, 2009).

Nesse discurso, é possível perceber que as proposições sinalizam, por um lado, para a formação de um indivíduo essencialmente econômico e privado e, por outro, para a constituição de um modelo de cidadão com reflexibilidade social; de um sujeito proativo, com três preocupações essenciais: a família; a comunidade e o meio ambiente; de um sujeito que ainda teria como valor moral o individualismo possessivo ${ }^{10}$, mas que, em determinadas situações emergenciais, seria capaz de sobrepujá-lo para o exercício da responsabilidade social (MARTINS, 2009). Esse indivíduo seria, portanto, capaz de reforçar os valores democráticos e a vida coletiva, de manter a coesão social e de fortalecer o crescimento econômico (LAVAL, 2004).

As cinco dimensões do Big Five que caracterizam o novo ideal de homem que se propõe formar correspondem a comportamentos que se circunscrevem à prática de voluntariado na comunidade em que o indivíduo tem suas raízes, ou a interesses pontuais da minoria de que faz parte. Em outras palavras, tem como fim colaborar para manter a miserabilidade em padrões aceitáveis, sem questionar a ordem social ou exercer uma atuação política mais abrangente na luta por direitos sociais universais (MARTINS, 2009).

Os princípios formativos contidos no Projeto SENNA correspondem, portanto, às necessidades de manutenção da coesão social em um contexto marcado pela violência crescente ${ }^{11}$. Os dados apontam para o aumento da criminalidade, do desemprego, do comércio ilícito, do terrorismo, do consumo de drogas, da miserabilidade e do fluxo de imigração mundial, dentre outros problemas que trazem à tona o aumento das tensões e conflitos sociais e colocam em cheque o poder dos Estados e o próprio capitalismo (HOBSBAWM, 2007).

\footnotetext{
10 Conforme Afonso (2009, p. 45), “[...] assume-se que os indivíduos são proprietários não só dos seus bens materiais, mas também de sua próprias capacidades, devendo ser livres para as pôr [sic] em prática em uma sociedade composta por outros indivíduos iguais e livres".

11 Os índices de violência desde 2008 têm aumentado muito, considerando homicídios, conflitos civis e militares (BRASIL 247, 2013).
}

Práxis Educativa, Ponta Grossa, p. 775-794, v. 11, n. 3, set./dez. 2016 Disponível em: <http://www.revistas2.uepg.br/index.php/praxiseducativa> 
Diante da realidade concreta, cujas marcas são a instabilidade da vida social, o crescente individualismo, a perda de direitos fundamentais e a falta de condições dignas de vida, a escola emerge como uma instituição responsável por formar sujeitos mais autônomos, tolerantes, solidários e estáveis emocionalmente. Deve, então, abandonar tudo o que pareça estar associado a conteúdos curriculares ultrapassados e supérfluos (PERRENOUD, 1999) para ensinar os sujeitos a ser resilientes, ou seja, a cultivar a força interior para agir de maneira positiva e não se acomodar, a se abrir para novas experiências, inventar novas alternativas de vida, superar dificuldades, ser sociável para resolver conflitos por meio da negociação e do debate pacífico.

A escola é desafiada a trabalhar em correspondência com as novas condições de vida. Os alunos devem ser avaliados nas dimensões como autoconceito (a imagem que fazemos de nós), autoeficácia (a capacidade, a expectativa que temos sobre nós mesmos para realizar algo), autoestima (avaliação positiva ou negativa que fazemos de nós) e lócus de controle (capacidade de responsabilizar aspectos internos ou externos por sucessos ou fracassos) (PRIMI; SANTOS, 2014).

Embora a proposta de avaliação do Projeto SENNA ainda esteja em fase de experimentação, já se cogita a possibilidade de premiar escolas que apresentem bons resultados nas dimensões contempladas na matriz de referência (PRIMI; SANTOS, 2014). Há, também, discussões sobre a necessidade de reestruturação curricular para incluir competências socioemocionais nos currículos escolares (IAS; UNESCO, [2013]).

No documento Competências socioemocionais: material de discussão, elaborado pelo Instituto Ayrton Senna em colaboração com a UNESCO, é apresentado um roteiro para orientar as práticas avaliativas e guiar a prática pedagógica na sala de aula. Nesse roteiro são descritas cinco ações, no âmbito das políticas públicas educacionais, para desenvolver um conjunto de competências para o século 21, dentre elas a reestruturação curricular. Para compor um currículo denominado inovador, o documento orienta que sejam combinados aspectos cognitivos e socioemocionais (IAS; UNESCO, [2013]).

Esta indicação leva-nos a considerar que existe uma indução para que, por meio da avaliação, sejam promovidas alterações no currículo escolar. Existe, também, uma solicitação para que sejam formuladas leis, portarias e decretos para amparar essas mudanças ${ }^{12}$.

Considerando que as avaliações não são neutras, mas marcadas por disputas políticas e ideológicas, devemos refletir sobre o fato de que esse modelo avaliativo não é desinteressado, principalmente por estar sendo formulado por uma organização que, além de representar os interesses privados ${ }^{13}$, passa a influenciar o sistema de avaliação, os currículos escolares e, consequentemente, a institucionalização de um novo paradigma de sistema educacional.

\section{Conclusão}

Nos encaminhamentos das reformas educacionais dos anos de 1990, as avaliações externas transformaram-se em um dos pilares indutores de mudanças curriculares e práticas pedagógicas. No Brasil, inicialmente, essas avaliações tinham uma perspectiva conteudista,

\footnotetext{
12 De acordo com Francisco Cordão, conselheiro do Conselho Nacional de Educação (CNE), na Câmara da Educação Básica já teve início a discussão de um processo de reestruturação curricular que contemple as competências socioemocionais (G1 NOTÍCIAS, 2014).

13 O Instituto Ayrton Senna recebe financiamento de organizações como a Coca-Cola, Monsanto, Boeing, etc. (R7 NOTÍCIAS, 2013).
}

Práxis Educativa, Ponta Grossa, p. 775-794, v. 11, n. 3, set./dez. 2016 Disponível em: <http://www.revistas2.uepg.br/index.php/praxiseducativa> 
voltada para a aferição de aspectos acadêmicos. Posteriormente, porém, passaram a se orientar pelo modelo de competências. Diante disso, entendemos que "[...] a avaliação se torna um dos instrumentos de política educativa suscetível de modificar os modelos cognitivos e culturais dominantes na escola" (TANGUY, 1997, p. 41). Isto significa afirmar que as avaliações externas influenciam a forma como os professores avaliam e a maneira como operacionalizam os conhecimentos, ou seja, suas concepções pedagógicas.

Analisando a metodologia da Prova Brasil, cujo foco é mobilizar a inteligência fluida, observamos que essa avaliação não exige, necessariamente, o domínio de conceitos previamente assimilados. Consideramos que isso ocorre porque existe uma tendência nos direcionamentos políticos e pedagógicos, da qual faz parte a lógica das competências, da negação dos conhecimentos científicos e culturais e do papel da escola como responsável pela distribuição, o mais igualmente possível, dos conhecimentos sistematizados. Na nova concepção

[...] predominam vivências de sujeitos individuais, cuja apreensão da cultura universal é prejudicada pela atenção distraída e pela falta de memória que se observa, inclusive, nas construções de vidro que impedem a fixação de vestígios. Em suma, a humanidade desenvolveu e acumulou um patrimônio cultural incalculável, mas a experiência não torna este patrimônio parte constitutiva dos sujeitos. (GALUCH, 2014, p. 130).

A negação do uso de conceitos previamente assimilados, característica da perspectiva das competências, corresponde às marcas do nosso tempo, faz parte de uma sociedade que tende a abandonar os conceitos, as narrativas universais e a ciência como instrumento de interpretação racional do real. Este aspecto, além de favorecer o esvaziamento dos conteúdos escolares, contribui para a deterioração da memória coletiva, um fenômeno social que, conforme apontado por Alves (2011, p. 144-145), “[...] possui implicações em nossa capacidade de imaginar experiências futuras. A imersão no presente contínuo significa não apenas a destruição do passado, mas a deterioração da capacidade de construir cenas futuras e eventos imaginários".

Ao propormos esta reflexão, pretendemos questionar a metodologia subjacente às avaliações externas, o que significa chamar a atenção para o fato de que, por meio das novas correntes teóricas e pedagógicas, está em curso um processo de desvalorização ou secundarização dos conhecimentos socialmente construídos, com implicações negativas na ação educativa, dentre as quais a valorização do senso comum e das histórias do cotidiano, em detrimento dos conhecimentos sistematizados das diferentes áreas e universalmente validados. Isso corresponde ao esquecimento dos conceitos na ação educativa, bem como implica um enfraquecimento do conjunto de conhecimentos desenvolvidos ao longo da história humana (RAMOS, 2011).

Este aspecto é reforçado, tornando-se mais grave à medida que o alto desenvolvimento tecnológico tem permitido a objetivação dos conhecimentos na máquina e a simplificação do processo de trabalho (BRAVERMAN, 1981). Disso decorre que a memória humana e a aprendizagem de conceitos passam a ter pouco valor no mundo produtivo para a maioria da classe trabalhadora, com implicações para as práticas educacionais e avaliativas, conforme procuramos indicar no decorrer deste artigo.

No que diz respeito ao modelo avaliativo elaborado pelo Projeto SENNA, suas dimensões contemplam comportamentos essenciais para o mundo do trabalho. No entanto, um ponto importante é que a política educacional de avaliação também tem dado ênfase à questão do caráter e da personalidade, porque a própria dinâmica social tem produzido a deteriorização dos princípios e valores padronizados e dos laços sociais duradouros que nos unem como seres humanos e nos oferecem um senso de identidade sustentável (SENNETT, 2012). Assim, é preciso disseminar uma lógica de fortalecimento do estado emocional, tendo em vista as alterações que essa forma de viver pode acarretar na personalidade humana.

Práxis Educativa, Ponta Grossa, p. 775-794, v. 11, n. 3, set./dez. 2016 Disponível em: < http://www.revistas2.uepg.br/index.php/praxiseducativa > 
Embora a flexibilização e a fluidez do caráter sejam produtos da própria dinâmica social, a escola é acionada para desenvolver, nas pessoas, a força subjetiva necessária à crença na possibilidade de prosperidade, uma força tênsil para que não venham a sucumbir ${ }^{14}$ (SENNETT, 2012). Isso significa que, em um mundo no qual o trabalho é degradante e provoca sofrimento, a tendência apontada pelo Projeto SENNA é formar pessoas com volição e escrupulosidade para suportar atividades desgastantes (TOUGH, 2014), para se esforçarem sem esperar recompensas e, ainda, serem capazes de postergar seus direitos. No mundo em que impera a lógica da competitividade, do consumismo e do individualismo crescentes, é preciso educar as pessoas para que sejam amáveis, tenham confiança nos outros e sejam capazes de construir vínculos mais fortes, mantendo, entre si, compromissos e laços de lealdade, o que implica a responsabilidade de uns para com os outros.

Se, baseados na lógica das competências, formos levados a admitir que alguns indivíduos são mais competentes que outros, abstraindo questões de ordem social, materiais e históricas que repercutem na formação e escolha profissional, deixaremos de analisar que existe uma exclusão intrínseca ao capitalismo. Com uma análise dessa natureza, validaremos a falsa ideia de que as desigualdades sociais são problemas individuais de sujeitos que não foram suficientemente competentes para se qualificar, ou seja, responsabilizaremos o próprio trabalhador por sua formação e ainda poderemos justificar as desigualdades sociais como uma questão de competência ou incompetência pessoal; quer dizer, poderemos fazer uma análise pautada na aparência dos fatos.

$\mathrm{Na}$ escola, o modelo das competências como eixo de fundamentação de avaliações apresenta consequências, cuja gravidade consiste na precarização da formação mediante a secundarização da assimilação de conceitos sistematizados por parte do aluno. Os conhecimentos sistematizados não são assimiláveis por meio de experiências cotidianas, como reafirma a lógica das competências; pelo contrário, resultam de um trabalho escolar planejado, cujo objetivo é a apropriação dos resultados da ciência. Os conhecimentos sistematizados não se consolidam na observação direta dos objetos, como ocorre com os conceitos espontâneos: envolvem formas mais complexas e elaboradas de pensar, que potencializam nossas capacidades intelectivas (REGO, 2010).

Em outros termos, as proposições da pedagogia das competências e as avaliações pautadas nesse modelo não buscam avaliar ou contribuir para a apropriação de conceitos, a qual, segundo Vygostky (2000, p. 246), exige “[...] o desenvolvimento de uma série de funções como atenção arbitrária, a memória lógica, a abstração, a comparação e a discriminação [...] todos processos psicológicos [...] complexos [...]."

Com as reflexões levadas a termo neste artigo, esperamos ampliar o debate crítico sobre as políticas públicas de avaliações externas com ênfase nas competências, especialmente sobre a qualidade que elas estão avaliando. Temos, em vista, evitar que essas avaliações e as perspectivas que as alimentam sejam tomadas como modelos para a organização do trabalho escolar.

\section{Referências}

AFONSO, A. J. Avaliação Educacional: regulação e emancipação: para uma sociologia das políticas educativas contemporâneas. 4. ed. São Paulo: Cortez, 2009.

\footnotetext{
${ }^{14} \mathrm{Na}$ sociedade pautada no estímulo ao consumo desenfreado, na busca obsessiva pelo ter, a vida humana torna-se uma vida sem sentido e um campo fértil para as doenças da alma, como quadros de ansiedade, depressão, síndromes do pânico, etc. (ALVES, 2011).
}

Práxis Educativa, Ponta Grossa, p. 775-794, v. 11, n. 3, set./dez. 2016 Disponível em: <http://www.revistas2.uepg.br/index.php/praxiseducativa> 
ALVES, G. Trabalho e subjetividade: o espírito do toyotismo na era do capitalismo manipulatório. São Paulo: Boitempo, 2011.

ARAÚJO, C. H.; LUZIO, N. Avaliação da Educação Básica: em busca da qualidade e equidade no Brasil. Brasília; Instituto Nacional de Estudos e Pesquisas Anísio Teixeira, 2005.

BANCO MUNDIAL. Aprendizagem para todos: investir nos conhecimentos e competências das pessoas para promover o desenvolvimento. Estratégia 2020 para a educação do grupo. Resumo Executivo. Washington: Banco Mundial, 2011. Disponível em: < http:// siteresources.worldbank.org/EDUCATION/Resources/ESSU/463292-

1306181142935/Portguese_Exec_Summary_ESS2020_FINAL.pdf>. Acesso em: 03 abr. 2015.

BONAMINO, A. C. Tempos de avaliação educacional: O SAEB, seus agentes, referências e tendências. Rio de Janeiro: Quartet, 2002.

BONAMINO, A. C.; FRANCO, C. Avaliação e política educacional: o processo de institucionalização do SAEB. Cadernos de Pesquisa, n. 108, p. 101-132, nov. 1999. DOI: 10.1590/s0100-15741999000300005

BRASIL. Diário Oficial da República Federativa do Brasil. Portaria n ${ }^{\mathbf{0}}$ 1795, de 27 de dezembro de 1994, Seção I, $\mathrm{n}^{\circ}$ 246, 8 de dez. de 1994. Disponível em: $<$ http://pesquisa.in.gov.br/imprensa/servlet/INPDFViewer?jornal=1\&pagina $=92 \&$ data $=28 / 12$ /1994\&captchafield=firistAccess > Acesso em: 03 abr. 2015.

BRASIL. Ministério da Educação. SAEB 1993: Sistema Nacional de Avaliação da Educação Básica. INEP: Brasília, 1995.

BRASIL. Ministério da Educação. Parâmetros Curriculares Nacionais: Introdução. vol. 1. Brasília: MEC/SEF, 1997.

BRASIL. Ministério da Educação. Matrizes curriculares de referência para o SAEB. INEP, Brasília, $1998 . \quad$ Disponível em: <http://www.dominiopublico.gov.br/download/texto/me002747.pdf>. Acesso em: 22 set. 2014.

BRASIL. Ministério da Educação. Portaria no 931, de 21 de Março de 2005, Institui o Sistema de Avaliação da Educação Básica, composto pela Prova Brasil (Anresc) e pelo Saeb (Aneb). Diário Oficial da Republica Federativa do Brasil, Brasília, n 55, 22 de março de 2005. Disponível em: $<$ http://portal.inep.gov.br/ >. Acesso em: 10 mar. 2014.

BRASIL. Ministério da Educação. PDE: Plano de Desenvolvimento da Educação: Prova Brasil. Ensino Fundamental: matrizes de referência, tópicos e descritores. Brasília: SEB, Inep, 2008. Disponível em: $<$ http: $/ /$ portal.mec.gov.br/index.php?option $=$ com_docman\&view $=$ download\&alias $=7619$ provabrasil-matriz-pdf\&Itemid=30192> . Acesso em: 08 set. 2014.

BRASIL. Instituto Nacional de Estudos e Pesquisas Educacionais. Semelhanças e Diferenças. 2011. Disponível em: <http: portal.inep.gov.br/web/saeb/semelhancas-e>. Acesso em: 22 set. 2014. 
BRASIL. Diário Oficial da União da República Federativa do Brasil. Portaria $\mathbf{n}^{\mathbf{0}} \mathbf{4 8 2}$, de 7 de Junho de 2013. Dispõe sobre o Sistema de Avaliação da Educação Básica - SAEB. Disponível em: http://www.adur-rj.org.br/4poli/gruposadur/gtpe/portaria_482_7_6_13.htm Acesso em: 23 jul. 2015.

BRASIL. Fundação Coordenação de Aperfeiçoamento de Pessoal de Nível Superior - CAPES Edital $\mathbf{n}^{\mathbf{0}}$ 44, de 10 de julho de 2014. Dispõe sobre o Programa de Apoio à Formação de Profissionais no Campo das Competências Socioemocionais. Disponível em: http://www.capes.gov.br/images/stories/download/editais/Edital_44_2014_CompetenciasSoci oemocionais.pdf Acesso em: 24 nov. 2015.

BRASIL 247. A violência aumenta no mundo: é o que mostra mapa da paz em 2013. Disponível em: < http://www.brasil247.com/pt/247/revista> Acesso em: 03 jun. 2015.

BRAVERMAN, H. Trabalho e capital monopolista: degradação do trabalho no século XX. 3 . ed. Rio de Janeiro: Zahar, 1981.

CARVALHO, E. J. G. Reestruturação produtiva, reforma administrativa do Estado e gestão da Educação. Educação \& Sociedade, São Paulo, v. 10, n. 109, p. 1139-1166, set./dez. 2009. DOI: 10.1590/S0101-73302009000400011

CENTRO NACIONAL EUROPASS. Kit Europass: reconhecimentos de traços de personalidade. Programa de aprendizagem ao longo de toda a vida. [2013], p. 1-35. Disponível em: <http:/ /www.europass.pt/index.php?option=com_artigos\&cat=Downloads\&Itemid=104>. Acesso em: 07 mar. 2014.

DALE, R. Globalização e Educação: demonstrando a existência de uma "Cultura Educacional Mundial Comum" ou localizando uma "Agenda Globalmente Estruturada para a Educação"? Educação \& Sociedade, Campinas, v. 25, n. 87, p. 423-460, maio/ago. 2004. DOI: 10.1590/s0101-73302004000200007

DELORS, J. Educação: um tesouro a descobrir. 6. ed. São Paulo: Cortez; Brasília: MEC; UNESCO, 1998.

DIAS SOBRINHO, J. Avaliação: políticas educacionais e reformas da educação. São Paulo: Cortez, 2003.

FÓRUM INTERNACIONAL DE POLÍTICAS PÚBLICAS "Educar para as competências do século 21". Competências para o Progresso Social. São Paulo: MEC/INEP/ Instituto Ayrton Senna, 2014a. Disponível em: <http://www.educacaosec21.org.br/foruminternacional2014/wpcontent/uploads/2014/01/Sao-Paulo-Forum_issues-paper-Portugues_final.pdf.>. Acesso em: 05 mar. 2015.

FÓRUM INTERNACIONAL DE POLÍTICAS PÚBLICAS "Educar para as competências do século 21”. Sumário: Fórum de Ministros. São Paulo, 2014b. Disponível em: <http://www.educacaosec21.org.br/foruminternacional2014/wp-

content/uploads/2014/01/SummaryPolicyMakersESPForum2014-PORT_v2.pdf>. Acesso em: 02 mar. 2015. 
FREITAS, L. C. Eliminação adiada: o ocaso das classes populares no interior da escola e a ocultação da (má) qualidade do ensino. Educação \& Sociedade, Campinas, v. 28, n. 100 Especial, p. 965-987, out. 2007. DOI: 10.1590/s0101-73302007000300016

G1 NOTÍCIAS. CNE estuda implantar conhecimentos socioemocionais na grade curricular das escolas. 10 de set de 2014. Disponível em: <http://www.administradores.com.br/noticia >. Acesso em: 12 ago. 2015.

GALUCH, M. T. B. O ensino nos anos iniciais do ensino fundamental: perspectiva de formação e práticas pedagógicas. Relatório Final de Pesquisa de Pós-Doutorado. Universidade de São Paulo. Instituto de Psicologia. Departamento de Psicologia da Aprendizagem, do Desenvolvimento e da Personalidade. São Paulo, 2014.

HOBSBAWM, E. Globalização, democracia e terrorismo. São Paulo: Companhia das Letras, 2007.

IANNI, O. A política mudou de lugar. In: DOWBAR, L. et.al. Desafio da Globalização. 3. ed. Petrópolis,: Vozes, 1997. p.17-27.

INSTITUTO AYRTON SENNA - UNESCO. Competências socioemocionais: material de discussão. [2013]. Disponível em: <educacaosec21.org.br>. Acesso em: 02 jul. 2015.

KUENZER, A. Z. Conhecimento e competências no trabalho e na escola. Boletim Técnico do SENAC, Rio de Janeiro, v. 28, n. 2, maio/ago. 2001. Disponível em: <www.senac.br/BTS/282/boltec282a.htm> Acesso em: 13 dez. 2014.

LAVAL, C. A Escola não é uma empresa: o neo-liberalismo em ataque ao ensino público. Londrina: Editora Planta, 2004.

LE BORTEF, G. Avaliar a competências de um profissional: três dimensões a explorar. Revista Reflexões de RH, p. 60-63, jun. 2006. Disponível em<www.guyleboterf-conseil.com> Acesso em 16 jan. de 2015.

LE GRAND, J. A outra mão invisível: a oferta de serviços públicos em regime de concorrência. Lisboa: Atual Editora, 2010.

MARTINS, A. S.. O neoliberalismo da Terceira Via: uma proposta para educar a sociabilidade. In: MARTINS, A. S. A direita para o social: a educação da sociabilidade no Brasil contemporâneo. Juiz de Fora: Editora UFJF, 2009, p. 59-110.

MORAES, M. C. M. Recuo da teoria: dilemas na pesquisa em educação. Revista Portuguesa de Educação, v. 14, n. 1, 2001, p. 7-25.

PERRENOUD, P. Avaliação: da excelência à regulação das aprendizagens-entre duas lógicas. Porto Alegre: Artes Médicas Sul, 1999.

PERRENOUD, P. Ensinar: agir na urgência, decidir na incerteza. 2. ed. Porto Alegre: Artmed, 2001. 
PRIMI, R.; SANTOS, D. Desenvolvimento socioemocional e aprendizado escolar: uma proposta de mensuração para apoiar as políticas públicas. São Paulo: OCDE, Instituto Airton Senna, Governo do Rio de Janeiro, 2014.

PRIMI, R.; SANTOS, A. A. A.; VENDRAMINI, C M.; TAXA, F.; MULLER, F. A.; LUKJANENKO, M. F.; SAMPAIO, I. S. Competências e Habilidades Cognitivas: diferentes Definições dos Mesmos Construtos. Psicologia: teoria e pesquisa, Brasília, v. 17, n. 2, maio/ago. 2001. p. 151-159. DOI: 10.1590/s0102-37722001000200007

R7 NOTÍCIAS. Show das poderosas: conheça as dez mulheres mais ricas e influentes do Brasil. 20 ago. 2013. Disponível em: <http://noticias.r7.com/economia/fotos/>. Acesso em: 14 jul. 2015.

RAMOS, M. N. A pedagogia das competências: autonomia ou adaptação? 4. ed. São Paulo: Cortes, 2011.

REGO, T. C. A cultura torna-se parte da natureza. IN: REGO, Teresa Cristina Vygostky: uma perspectiva histórico-cultural da educação. 21. ed. Petrópolis: Vozes, 2010, p. 37-83.

ROPÉ, F.; TANGUY, L. (Orgs.). Saberes e competências: o uso de tais noções na escola e na empresa. Campinas: Papirus, 1997.

SENNETTT, R. A corrosão do caráter: o desaparecimento das virtudes com o novo capitalismo. Rio de Janeiro: BestBolso, 2012.

SHIROMA, E.; EVANGELISTA, O. Avaliação e responsabilização pelos resultados: atualizações nas formas de gestão de professores. Perspectiva, Florianópolis, v. 29, n. 1, p. 127160, jan./jun. 2011.

SILVA, M. A. Intervenção e consentimento: a política educacional do Banco Mundial. Campinas: Autores Associados, 2002.

TANGUY, L. Racionalização pedagógica e legitimidade política. In: ROPÉ, F.; TANGUY, L. (Orgs). Saberes e competências: o uso de tais noções na escola e na empresa. Campinas: Papirus, 1997, p. 25-68.

TOUGH, P. Uma questão de caráter: por que a curiosidade e a determinação podem ser mais importantes que a inteligência para uma educação de sucesso. Rio de Janeiro: Intrínseca, 2014.

VIGOSTSKI, L. S. Estudo do desenvolvimento dos conceitos científicos na infância. In: VIGOSTSKI, L. S. A construção do pensamento e da linguagem. São Paulo: Martins Fontes, 2000, p. 241-394.

ZARIFIAN, P. O modelo de competências: trajetória histórica, desafios atuais e propostas. São Paulo, Editora SENAC, 2003.

Recebido em 24/12/2015

Versão corrigida recebida em 10/06/2016

Aceito em 12/06/2016

Práxis Educativa, Ponta Grossa, p. 775-794, v. 11, n. 3, set./dez. 2016 Disponível em: <http://www.revistas2.uepg.br/index.php/praxiseducativa> 